\title{
EEN VERSLAG VAN DEN COMMANDEUR DER KOLONIE ESSEQUEBO PIETER VAN DER HEIJDEN REZEN AAN DE KAMER VAN ZEELAND DER WEST-INDISCHE COMPAGNIE OVER DEN AANVAL VAN FRANSE KAPERS IN FEBRUARI 1709 i)
}

\author{
MEDEGEDEELD DOOR C. H. DE GOEJE
}

Edelachtbare Heren, Bewindhebbers van de Edele geoctroyeerde West-Indische Compagnie, Kamer van Zeeland.

Mijn welgebiedende,

Op den eersten Januari zond ik Haren Ed. a. mijn laatste missive met schipper Dirk van Leeuwen die, tegen zijn belofte aan schipper[?] Pr. Sijbrants, wegzeilde zonder mijn brieven en de boeken van deze rivier; ik zond ze echter terstond over land naar Berbice met Jan Baptista en een Creool en daar vonden zij dien van Leeuwen gereed tot vertrek. Door zijn plotseling vertrek konden de ladingpapieren niet ondertekend worden.

In voornoemd schip de Savoyard laadde ik voor H. E. a.

1) Het oorspronkelijk verslag is destijds door P. M. Netscher (Geschiedenis van de Koloniën Essequebo, Demerary en Berbice, 's-Gravenhage 1888 p. 101) niet aangetroffen in het Algemeen Rijksarchief en ontbreekt daar ook thans nog. Het stuk is echter in het Public Record Office te London aangetroffen door den Reverend James Williams, F. R. Hist. S., die het copieerde en in het Engels vertaalde. Dat Engelse stuk, omgezet in hedendaags Nederlands, volgt hier. Door het copiëren en twee keer vertalen zal het niet in alle details nauwkeurig wezen, maar als geheel is het toch wel bruikbaar.

Williams, die in Brits Guiana heeft gewoond, en van wiens hand belangrijke werken over Indianen en over geschiedenis zijn verschenen, overleed 28 November 1940. Hij was van plan dit verslag op te nemen in een nieuw werk ,Fort Kijk-over-al and the Dutch Colony of Isekebe, now Essequebo', hetwelk echter waarschijnlijk niet meer is uitgegeven geworden. 
.... vaten suiker, vijftig vaten oriana verf en vijf vaten maraan olie 1).

In mijn vorige missive schreef $\mathrm{ik}$ zeer uitvoerig aan H.Ed.a. over de maatregelen die ik tijdens die moeilijkheden had te nemen en wat er is voorgevallen. Ik verwijs naar voorschreven largo missive en zal nu overgaan tot het belangrijkste. Deze brief zal via Suriname aan H.Ed.a. verzonden worden en als de Almachtige God mijn leven zo lang wil sparen, zal ik nogmaals via Berbice voorschreven langen brief en dezen zenden en ook het garnizoensboek enz.

Op den 6en Februari jongstleden ontving ik een brief van mijn uitlegger ${ }^{2}$ ) in Demerara, meldend dat de Fransen met een bewapend schip met omtrent veertig man aldaar op zijn post geweest waren en alles hadden stuk geslagen en geplunderd, maar dat zij op denzelfden dag, zijnde de vierde, vertrokken waren, zonder er in geslaagd te zijn gevangenen te maken.

Toen ik des avonds deze tijding ontving waarschuwde ik onmiddellijk alle inwoners.

Tegen den middag arriveerde op het Fort een der brandwachten, zijnde een van der Edele Comp.'s uitlopers, buis Pieterse [?] die, na behoorlijk alarmseinen te hebben gegeven op de rivier, rapporteerde dat er op de rivier drie vijandelijke barken waren, een boot en verscheidene kleine vaartuigen; en dat Jan Broek ze gevolgd was tot Parika, waar hij ze had losgelaten. Daarop liet ik terstond signaalschoten afvuren, opdat al het volk naar het Fort zou komen.

Ik zond dadelijk Jan Theunissen stroomafwaarts op verkenning, die, toen hij bij de Compagnie's Plantage de Fortuijn was gekomen, daar den vrijen kolonist $\mathrm{R}$. de la Reviere ontmoette, die hem vertelde dat acht kleine vaartuigen op de plantage van den heer $\mathrm{Ab}$. Buisson waren, waarvan zij een groot deel hadden afgebrand, en voorts, dat de vijand ook geweest was op de plantage der Edele Cie. Wester Souburgh.

Den volgenden dag besloot ik de kanonnen van de Plantage de

1) oriaan $=$ rode verf die zich in de peulvruchten van de roekoestruik, Bixa orellana, bevindt; maraan $=$ hars van den hoepelhout boom, Copaifera Guyanensis; beide werden door ruilhandel van de Indianen verkregen (Netscher p. 91).

2) Hier en daar in het binnenland waren kleine postjes gelegd, bestaande uit één of twee Europeanen, ,uitleggers” genaamd, soms met een paar negers er bij, om handel te drijven met de meer verwijderd wonende Indianenstammen (Netscher p. 92). 
Vrijheijt weg te nemen en naar het Fort te brengen om dit te versterken. 's Nachts werd zwaar vuren benedenstrooms gehoord. Des zelfden daags dwong ik de bemanningen van twee Engelse barken die daar lagen, om naar het Fort te komen, onder bedreiging van ze tot zinken te brengen als zij onwillig zouden zijn.

In den avond van den 7en kwamen de Fransen met negen kano's en landden op Plantage de Vrijheijt, en terwijl zij meer dan duizend schoten losten, bestormden zij het huis, waar niemand meer was. Vanuit het Fort zagen wij dit begin van hun comedie in deze kolonie.

Op den 9den kon men de Franse vlag zien waaien op bovenvermelde plantage.

Op dat tijdstip had ik op het Fort vijftig Christenen die in staat waren wapenen te voeren, maar allen waren welgemoed.

In den ochtend waren de drie Franse barken ten anker gekomen voor de genoemde plantage.

Het werk op het Fort werd krachtig voortgezet, om den wal te sluiten.

Op den 1 len zond ik enige Creolen om den vijand afbreuk te doen in een kreek genaamd Carrouee; tegen den avond kwamen zij terug, meldend dat zij enige Fransen hadden verwond en een gedood en zeven geweren hadden buitgemaakt.

In den ochtend van den 12 en komt een vaartuig van den vijand met de witte vlag, waarop ik den vaandrig Mathijs Thierens derwaarts zond en het raadslid Pr. Rodriges; en bij hun terugkomst meldden zij dat de commandant der drie Franse barken mij liet weten dat hij den vorigen dag de plantage Oosterbeek door een stormaanval genomen had en aan boord enige van mijn mensen had, die ernstig gekwetst waren, en of ik ze wou laten afhalen? Dit deed ik denzelfden dag. De zwaar gewonden zijn Pr. de Visscher, Pr. Tollenaar, Jan Henricus Fegé, Ab. Maes, Jan Marsde, opzichter van Pr. de Visscher, de kuiper van den heer Hollander, en de opzichter van Jochem Maximillaen, de andere op plantage Oosterbeek waren allen gevangen genomen.

In den avond met vier glazen werd-gezien dat de plantage van de Ed.Cie. genaamd Fortuijn in brand gestoken was.

Met negen glazen werd gezien dat er brand was op H.Ed.a's plantage Poelwijck en enige huizen van Creolen aan het vuur wer-

1) Het fort Kijk-over-al, centraal gelegen bij de samenvloeiing der rivieren Mazaruni, Cuyuni en Essequebo, alwaar van 1622 tot 1718 de zetel van het bestuur was gevestigd (Netscher p. 88). 
den geofferd. Des Zondags had ik het magazijn, de loge enz. op het Fort laten slopen en enige goederen laten overbrengen naar de Ed.Cie's broodplantage.

Op den 13en werd een schot afgevuurd en een prinsenvlag uitgestoken bij de Suiker Kreek; ik zond er een kano heen met Jan Antheunissen en hij kwam terug in het Fort, medebrengend den heer Heijlgendorp met zijn kuiper en enige negerslaven, aan wie geweren werden gegeven.

In den namiddag zag men een Frans vaartuig naderen met een prinsenvlag op het voorschip; daarop zond ik terstond den vaandrig Matthijs Thierens en den chirurgijn Johan Malgraeff om te vernemen wat zij wensten. Toen zij kort daarna terugkwamen brachten zij een brief, geschreven door den Commandant der drie vijandelijke schepen, wiens naam was Josef Watts, maarschalk [?], waarin hij, Watts, mij mededeelde dat hij in naam van zijn Koning, van mij de onvoorwaardelijke overgave van het Fort eiste; waarbij hij er voorts op wees, dat ik zou weten dat volgens het oorlogsrecht geen kwartier zou worden verleend indien ik zou wachten tot ik werd angevallen; derhalve bad hij tot God voor mijn heil en hij hoopte dat zijn brief voor mij aannemelijk zou wezen.

Nadat ik en de leden van den Raad den brief gelezen hadden, antwoordden wij dat het Fort van Essequebo zich niet konovergeven, alvorens het garnizoen getoond had dat zij mannen van eer waren, gelijk de plicht was van alle onderdanen van de Staten Generaal der Verenigde Nederlanden. En voorts dat wij het oorlogsrecht even goed kenden als hij, en dat wij hetzelve in voorkomend geval eveneens in acht zouden nemen; en ten slotte dat wij (op dezen zelfden goeden dag) met genoegen zijn komst bij het Fort zouden afwachten.

Nadat ik den brief van den vijand en ons antwoord aan het gehele garnizoen had medegedeeld, vroeg ik of een hunner er bezwaar tegen had; zonder uitzondering riepen zij gezamenlijk uit, dat de vijand maar op moest komen om het te beproeven met het Fort, en dat zij mij zouden helpen om het tot den laatsten druppel bloeds te verdedigen; verscheidenen hunner vroegen om de bloedvlag te hijsen, en ik had mijn redenen om zulks niet te doen. Daarop vertrok de vaandrig met het antwoord op hun brief, terwijl ik al het volk verzamelde op den stenen hoek en toen de boot van wal stak riepen zij hem drie maal toe Lang leve de Staten Generaal der Verenigde Nederlanden.

Even voor het aanbreken van den dag op den 14en zag men 
twaalf vijandelijke vaartuigen passeren tussen de eilanden buiten het Fort, en toen zij de ruimte hadden, schaarden zij zich in orde van een halve maan, met de bedoeling het Fort te bestormen. Daarop liet ik enige schoten afvuren en zij haastten zich om weg te gaan, en gingen gezamenlijk naar de Pl. Westerbeek, behorende aan den Heer J. Baete. Bij den vijand was een zekere man geheten François Kersey die drie of vier dagen tevoren toen hij op post was, was overgelopen naar de Fransen, en terwijl hij bij hen was, ons in deze zaak veel schade heeft berokkend.

Middelerwijl waren de mannen opgewekt en wensten dat de vijand zou komen.

Tussen acht en negen uur gaf ik enige schoten af op Sebasirana waar enige Fransen waren, waarop de vijand van daar wederom naar Pln. Westerbeek ging.

Dien zelfden ochtend zond ik een kano met mijn Creolen en den vrijen Indiaan Allaya [Attaya?] naar de Compagnies Brood Plantage om de goederen van den dominee te halen; toen hun boot vol was wilden zij afstoten, maar werden aangevallen door een troep Fransen; enigen der Creolen en de Indiaan Attaya moesten het bos in gaan, omdat $z \mathrm{ij}$ de boot niet meer konden bereiken en bij het terugtrekken schoten zij op elkaar en aldus deed ook de rest van mijn lieden die in de kano waren. Het was wonder dat geen van mijn mensen in de kano gewond werd, wijl wij van het Fort de kogels voor en achter en naast de kano op het water zagen aanslaan; spoedig daarna liet ik de mensen die zich in het bos teruggetrokken hadden daaruit halen om naar het Fort terug te komen.

De Engelsen brengen hun victualie naar het Fort.

Dien dag lagen de vijandelijke barken tussen Brouwers Hoek en de Negerscop, bijna onder het bereik van mijn kanonnen; de gewonden verspreidden een pestilente lucht, weshalve wij veel lieten roken.

Het Fort is rondom bekleed met planken met spijkers om het bestormen moeilijk te maken; enige handgranaten en flessen kruit werden onder het volk verdeeld en elke punt kreeg een hoop zakken met musketkogels, om als schroot te dienen.

Op den 19en werden enige schoten afgevuurd op enige vijandelijke vaartuigen die naar de Cuyuni gingen. Op den 20en werd rook gezien in de Cuyuni wijl de Pl. Nieuw Middelburgh werd afgebrand.

Des namiddags arriveert een zekere persoon François Johannes 
spiernaakt op het Fort in een kleine korjaal, vluchtende van de Fransen, wiens rapport mij veel voldoening schonk [?].

Tegen den avond gaf ik last juffr. Baete af te halen van haar plantage en naar het Fort te brengen, daar zij slecht ter been was en half dood van honger en dorst en mijn vrouw droeg zorg voor haar.

De vijand deed al zijn best om enige vrouwen en kinderen buit te maken, bewerend dat zij ze op de voorplecht van hun vaartuigen zouden plaatsen en aldus het Fort zouden naderen; menend dat ik niet op mijn eigen mensen zou laten vuren, zouden zij op die wijze het Fort nemen zonder dat er een schot gelost was en iedereen massacreren, uitgezonderd drie personen, namelijk ikzelf, Pr. Rodriges en Michael Schaeber die zij aan den beul zouden overleveren.

Zij brachten hun verfoeielijk plan niet tot uitvoering, waarvoor wij den goeden God moeten danken.

Wij plaatsten grote tacouba balken en enige zware rotsblokken op de stenen punt en het plein, zodat deze als de vijand de plaats zou bestormen van boven neer zouden storten ${ }^{1}$ ).

Den 23 en bij de .... verbood ik de schildwachten op straffe van ophangen om iemand toe te staan zonder mijn verlof het Fort te verlaten.

Er komt een vijandelijk schip met witte vlag, waarop ik den vaandrig en $\mathrm{Ab}$. Buisson erheen zond, met last dat niemand mocht worden toegestaan het Fort te naderen.

Voornoemde personen kwamen terug met een brief die hun overhandigd was door den heer Jan de la Tombe, waarin al de krijgsgevangenen verzochten dat ik hen zou vrijkopen tegen vijf- en twintig slaven; ik antwoordde terstond dat ik daar niet in het geringst aan mee zoude doen, en dat de vijand, gelijk ik tevoren had gezegd, mocht proberen wat hij vermocht; wij zouden hem met genoegen opwachten.

Op den 24en gaven ik en de leden van den Raad last om twee negerslaven op het rad te binden, waar zij drie tot vier uren zouden blijven en dan den slag op het hart zouden krijgen en vervolgens in de rivier geworpen zouden worden tot voedsel voor de vissen. Deze executie geschiedde om vrees te verwekken onder de negers en weglopen (waartoe zij van plan waren) te voorkomen; de meeste goederen en slaven waren door dergelijke

1) takuba noemen de Arawakken een doden boomstam, zoals die dikwijls dwars over een smalle kreek ligt, en deze verspert. 
schelmen gewezen aan de Fransen die ze daarop wegvoerden. Dien ochtend dreven de drie Franse barken de rivier af.

In den namiddag werd een prinsenvlag gezien op Simirij, waarop ik terstond Jan Antheunissen per kano derwaarts zond; bij zijn terugkeer bracht hij naar het Fort den uitlegger van Wackepauw met meer dan vijftig Indianen; de uitlegger rapporteerde dat hij op den $21 \mathrm{en}$ in de Warwereijkoerij Kreek een treffen met den vijand had gehad, waarvan verscheidenen gedood en naar schatting veertig gewond waren, hetgeen ik en de andere vrienden met genoegen vernamen.

Den volgenden dag keerde bovenvermelde uitlegger Pr. de Blaeker met al zijn Indianen (na beloond te zijn voor hun diensten) naar zijn post terug met order bij de volgende volle maan met dezelfde Indianen weder op het Fort te komen.

Op den 25en lagen de vijanden ter hoogte van Stampers Eiland, nadat zij de plantage van Ab. Buisson en de Cie's Pl. Westersouburgh tot den grond toe hadden afgebrand.

Op den 27en kwamen in een rotte kano op het Fort aan, alle gevangenen, die den dag tevoren van nabij Parrika waren weggezonden door de Fransen; zonder een enkele uitzondering zagen zij eruit als struikrovers; nadat zij met mij het middagmaal hadden gebruikt, keerden zij naar Essequebo terug.

Op den 2 den van deze maand tussen acht en negen glazen, scheidde de Heer Johan Hendriques Fege van alles wat hij bezat in deze wereld, doordien er koud vuur bij zijn wonden was gekomen. Ook Jan Mars stierf na enige dagen.

Op den 8en stierf juffr. Baete op het Fort en overeenkomstig haar wens bracht de heer Hollander haar ter ruste op haar eigen plantage. Zij heeft drie jeugdige zoons achtergelaten waarvoor ik zo goed mogelijk zorg zal dragen, tot de heer Hollander instaat zal wezen voor hen te zorgen.

Van de gevangen vernamen wij met leedwezen dat de vijanden vastbesloten waren de vrouwen onder elkaar te verdelen en ze te misbruiken in tegenwoordigheid van hun gebonden echtgenoten; het oorlogsrecht veroorlooft iets dergelijks stellig niet en een ieder die enig Christelijk bloed in zijn aderen heeft zal er afschuw van hebben. Daarop hebben ik en mijn volk vast besloten om, indien wij opnieuw belegerd worden (wat God Almachtig verhoede) van den beginne af aan de bloedvlag te voeren ten teken dat geen kwartier verleend of aanvaard zal worden. Ziet, Ed. Mog. Heren, in welken toestand wij hier verkeren en hoe ik mijn leven lang een gunsteling van het geluk 
ben geweest; ik zal echter niet meer zeggen over mijzelf, daar mijn rampspoeden aan H. Ed. a. genoegzaam bekend zijn. Dit is het receyt, Ed. a., hetwelk ik in haast op papier stelde voor H. Ed. a. 's regering.

De kolonie is om zo te zeggen totaal geruineerd zonder hoop op herstel, wijl alle plantages verwoest zijn, de meeste slaven bij de Fransen zijn en meer dan 800 vaten suiker waarvan 500 voor rekening van H. E.d a., verbrand zijn.

Van de Pl. de Fortuijn zijn de meeste slaven verdwenen en eveneens van de Pl. Nieuwe Middelburgh, de Opperplanter van laatstgenoemd plantage heeft al zijn bezit in de wereld verloren, behalve het salaris dat hij te goed heeft. Van de Pl. Poelwijck en de Pl. Westersouburgh wordt, Goddank, bij deze moeilijkheden geen enkele slaaf vermist, zodat het belangrijkst verschil met den inventaris die aan $\mathrm{H}$. Ed. a. is toegezonden met schipper van Leeuwen, zal zijn enige doden.

Van de Broodplantage der Cie. ontsnapten bij deze troebelen naar de Fransen drie mannelijke slaven en hunne vrouwen, waaronder de beide smeden Prins en Cabrijt.

Op voormelde Broodplantage is tengevolge van het verbranden der gebouwen een grote hoeveelheid verf, pek, teer, touwwerk, zout enz. verbrand, waardoor ik verkeer in de ernstigste moeilijkheden ter wereld, als ik niet prompte hulp krijg van de ene of andere bron. Daarvoor heb ik Gouverneur en Raad van Suriname en eveneens den Gouverneur van Barbados om hulp gevraagd, hopend dat God zal maken dat mij een overwachte hulp zal toekomen, anders mogen Haar Ed. a.wel aannemen dat het zal wezen: Consummatum est.

Ik verlang naar instructies van H.Ed.a. zo spoedig mogelijk (als ik dan nog leef), of ik met de overblijvende slaven mij zal nederzetten in Demerara, welke rivier, gelijk velen getuigen, sterk bevestigd is; daarvoor zou ik dan materialen en werkvolk verzoeken.

Of dat H.Ed.a. besluiten dat ik met die slaven naar Suriname of elders moet gaan. Want zekerlijk biedt deze rivier met zijn Fort niet de geringste mogelijkheid om verdedigd te worden, zelfs indien meer benedenstrooms een of twee versterkingen werden opgericht, want een vijand kan de rivier langs drie of vier wegen binnenkomen, ondanks onze wachten die dagelijks buiten zijn.

Haar Ed.a. behoeven niet bezorgd te wezen dat de Kolonie Berbice ook binnenkort bezocht zal worden en er gevaar zal zijn 
dat de plantages verwoest zullen worden, wijl het ongelofelijk is hoe de vijanden door het bos zijn getrokken en ook boven de watervallen. Toch denk ik niet dat de vijand aan het fort aldaar enige schade zal toebrengen wijl het een genoegen is het te zien, want het is uitermate sterk en de Commandeur is nog steeds aan het werk. Hadde God gewild, dat H.Ed.a. 's Kijkoveral in denzelfden staat hadde verkeerd!

Maar H.Ed.a. mogen verzekerd zijn, dat H.E.a. 's voormeld Fort zeer veranderd is, wijl ik al de oude aarden wallen van pallissaden voorzien heb; ze zijn vlak gemaakt en de helft lager geworden en bezet met palissaden. Het is ,God zij dank, rondom afgesloten en bewapend met vijftig kanonnen, goed verdeeld en redelijk voorzien van kruit, en kogels ontbreken mij niet, noch kan ik klagen over het aantal geweren en ik heb, dank zij God nog een flink aantal handgranaten, ik heb echter nog lont nodig; maar ik twijfel niet of binnenkort zullen wij dit te boven komen. Tenslotte, H.Ed.a., ben ik zeker dat met zestig Christenen ik een aanval van driehonderd kan afslaan, als de Almachtige God zijn volk niet bezoekt met blooheid. Daarom zeg ik, gelijk de oude spreuk luidt: - 'si Deus pro nobis quis contra nos', en voorts, mijzelf troostend in de rampen die door den Heer zijn bevolen, zal ik mijn lijfspreuk volgen „Fidelle jusqu'a la mort".

Trachtend mijn vaderland en H.Ed.a. getrouwelijk te dienen.

Thans niet meer, H.Ed.a., dan dat ik, met onvoorwaardelijke onderdanigheid aan Hunne Edel Mogenden Bewinthebberen der eerwaardige Geoctroijeerde West-Indische Compagnie van den Raad van Tien, om verontschuldiging vraag dat ik met geen mogelijkheid meer heb kunnen doen dan ik gedaan heb.

Ten slotte bid ik God dat hij de plannen van H.Ed.a. doe slagen en dat $\mathrm{Hij}$ overvloedig den dauw $\mathrm{Zijner}$ genade sproeie over H.Ed.a. 's families en ons dierbaar Vaderland, en dat hij mijn zijn genade schenke en mijn leven nog enigen tijd spare voor H.Ed.a. en ons dierbaar Vaderland, en ik wil blijven en bereid tot offers, Hoog geeerde Heren.

H. Ed.a. 's nederige en tot den dood getrouwe dienaar

Pr. van der Heyden Rezen 1709. 